\title{
OPTIMALISASI PEMBELAJARAN DARING PADA MASA PANDEMI COVID 19 MELALUI MEDIA E-LEARNING PADA PROGRAM STUDI PPKN FKIP UNIVERSITAS PASUNDAN
}

\author{
Asep Deni Normansyah, Cep Miftah Khoerudin \& Cahyono \\ Program Studi PPKn FKIP Universitas Pasundan \\ asepdeninormansyah@unpas.ac.id, cepmiftahkhoerudin@unpas.ac.id, \& cahyono@unpas.ac.id
}

\begin{abstract}
Abstrak
Pandemi Covid 19 telah mengakibatkan perubahan signifikan dalam berbagai bidang termasuk dalam bidang pendidikan dan pembelajaran. Sistem daring bukan lagi sebuah opsi melainkan menjadi konsekuensi dalam situasi ini. Penelitian ini bertujuan untuk mengidentifikasi optimalisasi pembelajaran daring melalui E-Learning pada Program Studi PPKn FKIP Unpas. Metode yang digunakan yaitu studi deskriptif dalam pendekatan kualitatif. Teknik pengumpulan data menggunakan observasi wawancara dan studi dokumentasi, kemudian dibantu dengan kuisioner sebagai data pendukung. Hasil penelitian menunjukan bahwa proses pembelajaran daring pada program studi PPKn FKIP Unpas telah memiliki mekanisme yang baik sejak mulai regulasi perkuliahan, persiapan peningkatan keterampilan Sumber Daya Manusia untuk pembelajaran daring hingga media Learning Management System yang digunakan. Upaya peningkatan kualitas pembelajaran daring telah ditempuh oleh Program Studi PPKn FKIP Unpas yang dibuktikan dengan dilaksanakannya pelatihan tenaga pengajar secara periodik dan kontinu, hal tersebut mendukung optimalisasi pembelajaran daring yang dilaksanakan selama pandemic Covid 19. Dengan demikian berdasarkan hasil penelitian yang digunakan mengungkapkan bahwa pembelajaran daring pada masa pandemic Covid 19 melalui $e$ learning pada Program Studi PPKn FKIP Universitas Pasundan telah berjalan secara optimal. Namun masih terdapat beberapa hal yang masih dalam proses perbaikan seperti kualitas muatan materi dan konten dalam e-learning dan pemahaman pengajar dalam proses akses LMS pada e-learning.
\end{abstract}

Kata kunci: Pembelajaran daring, e-learning, PPKn, Pandemi Covid 19.

\begin{abstract}
The Covid-19 pandemic has resulted in significant changes in various fields including education and learning. The online system is no longer an option but a consequence in this situation. This study aims to identify the optimization of online learning through E-Learning in the PPKn FKIP Unpas Study Program. The method used is a descriptive study in a qualitative approach. Data collection techniques using interview observations and documentation studies, then assisted with questionnaires as supporting data. The results showed that the online learning process in the PPKn FKIP Unpas study program had a good mechanism starting from the regulation of lectures, preparation for improving the skills of Human Resources for online learning to the Learning Management System media used. Efforts to improve the quality of online learning have been taken by the PPKn FKIP Unpas Study Program as evidenced by the implementation of periodic and continuous training of teaching staff, this supports the optimization of online learning carried out during the Covid 19 pandemic. During the Covid 19 pandemic through $e$ learning at the PPKn FKIP Study Program, Pasundan University has run optimally. However, there are still some things that are still in the process of being improved, such as the quality of content and content in e-learning and the understanding of teachers in the process of accessing LMS on e-learning.
\end{abstract}

Keywords: Online learning, e-learning, PPKn, Covid 19 pandemic.

\section{PENDAHULUAN}

Pandemi COVID-19 saat ini telah membawa perubahan pada metode pembelajaran jarak jauh (PJJ). Juga menyediakan berbagai aplikasi media pembelajaran, termasuk pemerintah dan swasta. Namun, selama pandemi Covid-19, perdebatan publik tentang penyimpangan muncul. Perguruan tinggi yang dulu menerapkan metode tatap muka secara 
penuh dalam perkuliahan, bimbingan esai, dan kegiatan akademik lainnya kini perlu mengubahnya ke metode PJJ. Di luar negeri, itu disebut pembelajaran jarak jauh. Dalam berbagai penelitian lain disebut juga sebagai pembelajaran online, e-learning ( $e$ learning) dan online (di web). Sekarang ini menjadi tantangan bagi dosen, dan mahasiswa mau tidak mau harus siap menghadapi pembelajaran online yang ada (Tîrziu \& Vrabie, 2015). Perbedaan pembelajaran tatap muka dengan PJJ memberikan pengaruh yang berbeda terhadap kualitas belajar siswa (Karwati, 2014).

Guru atau dosen bukan satu-satunya tonggak penentu (Rachman et al., 2021). Ini merupakan tantangan berat bagi guru, dosen, dan orang tua. Banyak orang tua yang mengeluhkan media pembelajaran jarak jauh (Internet) online ini (Dewantara, Nurgiansah, et al., 2021) (Dewantara, Hermawan, et al., 2021). Khusus untuk orang tua yang bekerja di rumah (WFH), harus tetap mendampingi anaknya, terutama anaknya yang masih dalam masa pertumbuhan. Hal ini dikarenakan teknologi yang diperkenalkan tidak merata ketika menggunakan media pembelajaran (seperti laptop, gadget, dll). (Miarso, 2004, hlm. 78).

Dalam rangka beradaptasi dengan masa adaptasi kebiasaan baru, prodi PPKn FKIP Universitas Pasundan menggunakan media e-learning Moodle dan UBL untuk pembelajaran online. Kedua media tersebut digunakan untuk pembelajaran online siswa. Oleh karena itu, perlu dilakukan secara maksimal untuk mengoptimalkan pembelajaran online sumber daya manusia dan/atau konten materi yang terkandung dalam media.

\section{METODE PENELITIAN}

Dalam penelitian ini Metode yang digunakan dalam penelitian ini adalah studi deskriptif dengan pendekatan kualitatif yaitu metode yang menitik beratkan perhatian nya pada peristiwa atau kejadian yang sedang berlangsung dan akibatnya dikemudian hari dianalisis.

Arikunto (2013:243). Selain itu pendapat lain yang dikemukakan Syaodih (2007:72): "Penelitian deskriptif adalah suatu bentuk penelitian yang paling dasar, ditujukan untuk mendeskripsikan atau menggambarkan fenomena fenomena yang ada, baik fenomena yang bersifat alamiah atau rekayasa manusia. Penelitian deskriptif mengkaji aktivitas, karakteristik, perubahan, hubungan, kesamaan dan perbedaannya dengan fenomena lain.

Pengumpulan data digunakan melalui teknik observasi, wawancara, dokumentasi dan kuisioner yang kemudian di analisis menggunakan reduksi, penyajian data dan penarikan kesimpulan

\section{HASIL PENELITIAN DAN PEMBAHASAN Hasil Penelitian}

Pembelajaran daring pada Program Studi PPKn FKIP Universitas Pasundan dilaksanakan melalui media Learning Management System (LMS) yang dalam hal ini menggunakan moodle dengan mekanisme yang terstuktur dan sistematis berdasarkan aturan dari pimpinan fakultas. Dalam pengelolaannya pembelajaran daring pada Program Studi PPKn FKIP Universitas Pasundan dengan membentuk tim pengembang yang terdiri dari tim pengembang dari fakultas dan program studi.

Berdasarkan hasil observasi dan dokumentasi mekanisme pembelajaran daring pada Program Studi PPKn FKIP Universitas Pasundan diawali dengan memasukkan mahasiswa (enroll) kedalam kelas yang telah dibuat sesuai dengan struktur kurikulum yang digunakan. Kemudian data mahasiswa akan dimasukan kedalam kelas sebagai anggota dari kelas tersebut sesuai dengan data 
mata kuliah yang dikontrak pada Kartu Rencana Studi. Setelah itu mahasiswa dapat mengakses media pembelajaran yang disajikan oleh dosen dalam setiap topik perkuliahan.

Mahasiswa akan berinteraksi dengan dosen melalui dua tipe perkuliahan yakni perkuliahan Syncronous atau tatap muka terekam yang menggunakan media video teleconference baik zoom, google meet dan sejenisnya. pada tahap ini mahasiswa akan melakukan perkuliahan tatap muka virtual dengan dosen untuk menyampaikan materi perkuliahan serta dapat digunakan sebagai media interaksi antara mahasiswa dan dosen pada selama proses pembelajaran berlangsung.

Jenis pembelajaran yang kedua adalah pembelajaran asyncrounous atau pembelajaran tanpa tatap muka melainkan dalam bentuk interaksi baik berupa diskusi maupun penugasan bagi mahasiswa. Pada tahap ini mahasiswa akan belajar secara mandiri dengan mengakses media yang disajikan dosen dalam LMS baik berupa diskusi atau penugasan.

Untuk mendukung hasil penelitian maka dilakukan survey terhadap sampel mahasiswa pada Program Studi PPKn FKIP Universitas Pasundan terhadap optimalisasi pembelajaran dari terkhusus dimasa pandemic Covid 19 yang disajikan sebagai berikut:

\section{a. Kemudahan interaksi pembelajaran daring}

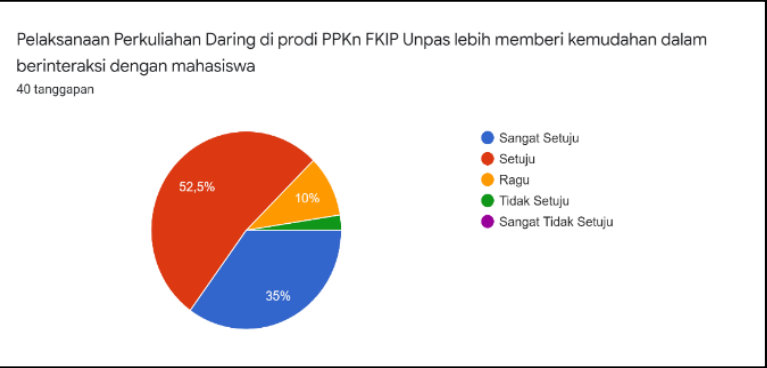

Grafik 4.1. Hasil Survei Kemudahan Interaksi Pembelajatan daring
Berdasarkan grafik diatas dapat diketahui bahwa dari sampel mahasiswa yang diberi kuisioner pada Program Studi PPKn FKIP Universitas Pasundan menyatakan bahwa 52,5\% atau lebih dari setengahnya menyatakan pembelajaran daring pada Program Studi PPKn FKIP Universitas Pasundan memberikan kemudahan dalam berinteraksi antara mahasiswa dan dosen, 35,0\% atau sebagian besar mahasiswa menyatakan sangat setuju bahwa pembelajaran daring pada Program Studi PPKn FKIP Universitas Pasundan memberikan kemudahan dalam berinteraksi antara mahasiswa dan dosen, $10 \%$ atau sebagian kecil menyatakan ragu dan 2,5\% atau hampir tidak ada menyatakan tidak setuju bahwa pembelajaran daring pada Program Studi PPKn FKIP Universitas Pasundan memberikan kemudahan dalam berinteraksi antara mahasiswa dan dosen.

Merujuk pada hasil survei diatas peneliti berpendapat bahwa pembelajaran daring pada Program Studi PPKn FKIP Universitas Pasundan telah mampu menjadi media interaksi yang baik melalui mekanisme yang dilaksanakan dengan efektif dan efisien.

\section{b. Kemudahan Akses Pembelajaran Daring}

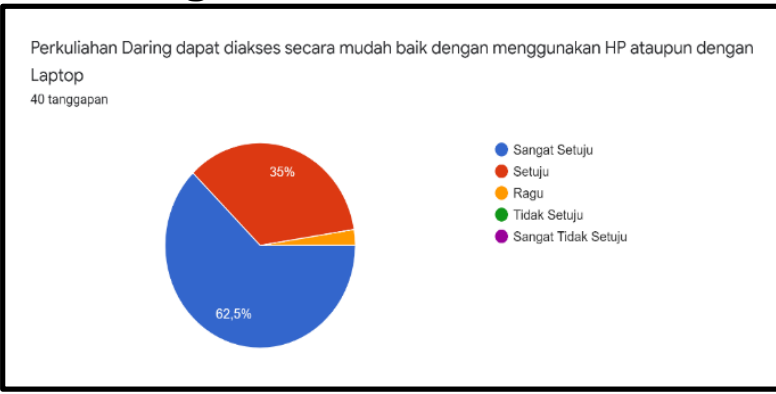

Grafik 4.2. Hasil Survei Kemudahan akses Pembelajaran daring

Berdasarkan grafik diatas dapat diketahui bahwa dari sampel mahasiswa yang diberi kuisioner pada Program Studi PPKn FKIP Universitas Pasundan 
menyatakan bahwa $62,5 \%$ atau hampir seluruhnya menyatakan pembelajaran daring pada Program Studi PPKn FKIP Universitas Pasundan memberikan kemudahan akses untuk mahasiswa dan dosen, 35,0\% atau sebagian besar mahasiswa menyatakan sangat setuju bahwa pembelajaran daring pada Program Studi PPKn FKIP Universitas Pasundan memberikan kemudahan akses untuk mahasiswa dan dosen, 4,5\% atau sebagian kecil menyatakan ragu bahwa pembelajaran daring pada Program Studi PPKn FKIP Universitas Pasundan memberikan kemudahan untuk diakses oleh mahasiswa dan dosen.

Berdasarkan pada hasil penelitian yang diuraikan diatas peneliti berpendapat bahwa pembelajaran daring yang dilakukan pada Program Studi PPKn FKIP Universitas Pasundan telah dilakukan sesuai dengan mekanisme yang ditentukan serta sesuai dengan aturan yang berlaku. Hal ini mendukung ketercapaian optimalisasi pembelajaran daring pada masa pandemi covid 19 yang dilaksanakan di Program Studi PPKn FKIP Universitas Pasundan.

Berbagai upaya untuk menekan mata rantai penyebaran Covid-19 di lingkungan kampus, menerapkan aturan pembelajaran daring. Perkuliahan dilakukan menggunakan internet sehingga memudahkan dosen dan mahasiswa berinteraksi secara on line. Dosen dapat membuat bahan ajar yang dapat diakses oleh mahasiswa dimana saja dan kapan saja. Program Studi PPKn FKIP Universitas Pasundan melakukan berbagai upaya persiapan dalam pembelajaran daring baik untuk mahasiswa maupun dosen di lingkungan Program Studi PPKn FKIP Universitas Pasundan.

Dalam upaya meningkatkan keterampilan mahasiswa dalam menggunakan LMS Program Studi PPKn FKIP Universitas Pasundan melakukan berbagai sosialisasi dan pelatihan bagi mahasiswa secara periodik dan kontinu. Sosialisasi pembelajaran daring dilakukan pada mahasiswa Program Studi PPKn FKIP Universitas Pasundan di awal masa berlakunya pembelajaran daring yang dilakukan oleh pimpinan Program Studi PPKn FKIP Universitas Pasundan dan fakultas. Kemudian diberikan pula pelatihan penggunaan LMS yang dilakukan oleh admin Program Studi PPKn FKIP Universitas Pasundan agar mahasiswa dapat menggunakan LMS dengan baik.

Sedangkan untuk mempersiapkan tenaga dosen dalam pembelajaran daring Program Studi PPKn FKIP Universitas Pasundan bekerja sama dengan fakultas melakukan pelatihan penggunaan LMS secara periodik dalam tiap semester. Pelatihan terdiri dari dua tahap yakni tahap pertama dosen diberi pemahaman tentang muatan dan konten LMS sedangkan tahap kedua dosen dibimbing melakukan praktik pengelolaan LMS dengan tutor dari masing-masing program studi.

\section{Pembahasan}

Dalam proses pembelajaran secara daring (online) ini memberikan banyak sekali dampak, mulai dari dampak positif hingga dampak negatif. Pembelajaran secara daring (online) ini guru dituntut untuk mempersiapkan pembelajaran sebaik dan sekreatif mungkin dalam memberikan suatu materi. Berdasarkan pemaparan tersebut bahwa pembelajaran daring di masa pandemic covid 19 menjadi tantangan baru juga pada Program Studi PPKn FKIP Universitas Pasundan yang telah melaksanakan pembelajaran daring dengan mekanisme yang berlaku baik dari tingkat universitas fakultas dan diimplementasikan pada tingkat Program Studi PPKn FKIP Universitas Pasundan. Pembelajaran daring menggunakan media LMS MOODLE yang dirancang dan 
disesuaikan dengan pola pembelajaran yang berlaku.

Hal ini sesuai pendapat yang mengemukakan Pembelajaran daring menghubungkan peserta didik dengan sumber belajarnya (database, pakar/ instruktur, perpustakaan) yang secara fisik terpisah atau bahkan berjauhan namun dapat saling berkomunikasi, berinteraksi atau berkolaborasi (secara langsung/ synchronous dan secara tidak langsung/ asynchronous). Pembelajaran daring adalah bentuk pembelajaran jarak jauh yang memanfaatkan teknologi telekomunikasi dan informasi, misalnya internet, CDROOM (Arizona, 2020) (Nurgiansah, 2021).

Program Studi PPKn FKIP Universitas Pasundan melakukan berbagai upaya persiapan dalam pembelajaran daring baik untuk mahasiswa maupun dosen di lingkungan Program Studi PPKn FKIP Universitas Pasundan. Dalam upaya meningkatkan keterampilan mahasiswa dalam menggunakan LMS Program Studi PPKn FKIP Universitas Pasundan melakukan berbagai sosialisasi dan pelatihan bagi mahasiswa secara periodik dan kontinu. Sosialisasi pembelajaran daring dilakukan pada mahasiswa Program Studi PPKn FKIP Universitas Pasundan di awal masa berlakunya pembelajaran daring yang dilakukan oleh pimpinan Program Studi PPKn FKIP Universitas Pasundan dan fakultas. Kemudian diberikan pula pelatihan penggunaan LMS yang dilakukan oleh admin Program Studi PPKn FKIP Universitas Pasundan agar mahasiswa dapat menggunakan LMS dengan baik.

Sedangkan untuk mempersiapkan tenaga dosen dalam pembelajaran daring Program Studi PPKn FKIP Universitas Pasundan bekerja sama dengan fakultas melakukan pelatihan penggunaan LMS secara periodik dalam tiap semester. Pelatihan terdiri dari dua tahap yakni tahap pertama dosen diberi pemahaman tentang muatan dan konten LMS sedangkan tahap kedua dosen dibimbing melakukan praktik pengelolaan LMS dengan tutor dari masing-masing program studi.

Hal tersebut sesuai dengan pendapat yang mengemukakan Penggunaan pembelajaran daring menggunakan zoom cloud meeting memiliki kelebihan dapat berinteraksi langsung antara mahasiswa dan dosen serta bahan ajar tetapi memiliki kelemahan boros kuata dan kurang efektifapabila lebih dari 20 peserta didik (Naserly, M. K.,2020).

\section{KESIMPULAN}

Merujuk pada hasil penelitian yang dilakukan peneliti dan hasil pembahasan yang dibahas melalui teori yang berkembang maka dapat diberikan bebrrapa kesimpulan dalam penelitian ini yaitu sebagai berikut Pertama, mekanisme pembelajaran daring yang dilakukan pada Program Studi PPKn FKIP Universitas Pasundan dilaksanakan secara terstruktur dan sistematis diawali dari mendaftarkan mahasiswa sebagai peserta kursus mata kuliah sampai dengan proses pembelajaran berlangsung. Selain itu didukung dengan hasil survei yang dilakukan pada mahasiswa yang mendapat hasil bahwa sebagian besar mahasiswa mearasa puas dengan mekanisme pembelajaran daring pada Program Studi PPKn FKIP Universitas Pasundan.

Kedua, berbagai upaya persiapan dilakukan oleh Program Studi PPKn FKIP Universitas Pasundan dalam efisisensi pembelajaran daring pada masa pandemic covid 19 dimulai dari pelatihan dosen secara periodik dan kontinu begitu pula dengan kesiapan mahasiswa dan pelatihan diberlakukan pula untuk dosen dalam menyiapkan konten materi pembelajaran yang dimuat dalam elearning. Selain itu hasil survei mahasiswa sebagian besar menyatakan setuju dengan persiapan yang 
dilakukan Program Studi PPKn FKIP daring.

Universitas Pasundan dalam pembelajaran

\section{DAFTAR PUSTAKA}

Arikunto, S. (2013). Prosedur Penelitian: Suatu Pendekatan Praktik. Jakarta: Rineka Cipta.

Arizona, K., Abidin, Z., \& Rumansyah, R. (2020). Pembelajaran online berbasis proyek salah satu solusi kegiatan belajar mengajar di tengah pandemi covid-19. Jurnal Ilmiah Profesi Pendidikan, 5(1), 64-70.

Dewantara, J. A., Hermawan, Y., Yunus, D., Prasetiyo, W. H., Efriani, Arifiyanti, F., \& Nurgiansah, T. H. (2021). Anti-Corruption Education as an Effort to Form Students With Character Humanist and Law-Compliant. Jurnal Civics: Media Kajian Kewarganegaraan, 18(1), 70-81.

Dewantara, J. A., Nurgiansah, T. H., \& Rachman, F. (2021). Mengatasi Pelanggaran Hak Asasi Manusia dengan Model Sekolah Ramah HAM (SR-HAM). Edukatif: Jurnal Ilmu Pendidikan, $3(2), 261-269$.

Karwati, E. (2014). Pengaruh Pembelajaran elektronik (e-learning) terhadap mutu belajar mahasiswa. Jurnal Penelitian Komunikasi, 17(1), 41-54.

Molinda, M. (2005), Instructional Technology and Media for Learning New Jersey Colombus, Ohio

Miarso, Y. (2004). Menyemai benih teknologi pendidikan. Kencana.

Naserly, M. K. (2020). Implementasi Zoom, Google Classroom, Dan Whatsapp Group Dalam Mendukung Pembelajaran Daring (Online) Pada Mata Kuliah Bahasa Inggris Lanjut (Studi Kasus Pada 2 Kelas Semester 2, Jurusan Administrasi Bisnis, Fakultas Ekonomi Dan Bisnis, Universitas Bina Sa. Aksara Public, 4(2), 155-165.

Nurgiansah, T. H. (2021). Pemanfaatan E-Learning Dalam Pembelajaran Pendidikan Kewarganegaraan. JINTECH: Journal of Information Technology, 2(2), 138-146.

Rachman, F., Nurgiansah, T. H., \& Kabatiah, M. (2021). Profilisasi Pendidikan Kewarganegaraan dalam Kurikulum Pendidikan Indonesia. Edukatif: Jurnal Ilmu Pendidikan, 3(5), 2970-2984.

Syaodih, E. (2007). Pengembangan Model Pembelajaran Kooperatif Untuk Meningkatkan Keterampilan Sosial. Educare.

Tirziu, A. M., \& Vrabie, C. (2015). Education 2.0: E-learning methods. Procedia-Social and Behavioral Sciences, 186, 376-380. 